\title{
Inovasi Mesin-Mesin Teknologi Pascapanen Kopi sebagai Produk Usaha Intelektual Kampus Politeknik Negeri Lhokseumawe
}

\section{Innovation of Coffee Postharvest Technology Machines as Campus Intellectual Business Products Lhokseumawe State Polytechnic}

\author{
1Indra Mawardi, ${ }^{1}$ Nurdin, ${ }^{2}$ Zulkarnaini \\ ${ }^{1}$ Jurusan Teknik Mesin, Politeknik Negeri Lhokseumawe, Aceh \\ 2Jurusan Tata Niaga, Politeknik Negeri Lhokseumawe, Aceh \\ Korespondensi: Indra Mawardi, indratm@pnl.ac.id
}

Naskah Diterima: 18 Juli 2019. Disetujui: 21 Januari 2020. Disetujui Publikasi: 23 Januari 2020

\begin{abstract}
The growth of the area of coffee plantations continues to increase every year needs to be supported by the readiness of postharvest technology that is suitable to be able to produce quality coffee beans. The Lhokseumawe State Polytechnic has taken the opportunity to form a business unit for the production of appropriate the technology of the postharvest coffee machine, through a service program with the scheme of the Campus Intellectual Product Business Development Program. The center for production of machinery for appropriate technology for postharvest coffee The Lhokseumawe State Polytechnic aims to increase the productivity of coffee farmers through the mechanization of the coffee postharvest process by innovating appropriate technology technologies for coffee postharvest. Besides that to support campus independence through the business of producing coffee postharvest machines. The method of implementing activities starts from machine design, provision of raw materials, production processes, to product marketing. From the results of the activity has been formed production centers of appropriate technology for postharvest coffee machines. The center for production of machinery appropriate technology postharvest coffee has made innovations in coffee postharvest technology machines. Innovative products from the machine production center for appropriate technology for postharvest coffee include mobile pulper machines, coffee bean washing machines, mobile huller machines and multi-functional hullers, coffee bean sorting machines, and vibrating systems. These machines have advantages of construction and mobilization compared to products that have been circulating in the market so far. Product marketing has been done through a showroom as a place to showcase products, sales websites, and online stores.
\end{abstract}

Keywords: Innovation, postharvest technology, coffee, campus intellectual products.

\begin{abstract}
Abstrak. Pertumbuhan luas perkebunan kopi terus meningkat setiap tahun perlu didukung dengan kesiapan teknologi pascapanen yang cocok untuk dapat menghasilkan biji kopi bermutu. Politeknik Negeri Lhokseumawe telah mengambil peluang tersebut dengan membentuk unit usaha teknologi tepat guna pascapanen kopi, melalui program pengabdian dengan skim Program Pengembangan Usaha Produk Intelektual Kampus (PPUPIK). Kegiatan PPUPIK ini bertujuan menunjang kemandirian kampus melalui usaha produksi mesin-mesin pascapanen kopi melalui inovasi dan produksi mesin-mesin TTG pascapanen kopi. Kegiatan ini pada akhirnya akan meningkatkan produktifitas petani kopi melalui mekanisasi proses pascapanen kopi yang baik. Metode kegiatan PPUPIK terbagi dalam tiga tahapan, yaitu tahapan produksi, pemasaran dan pendirian unit usaha. Tahapan produksi dimulai dari design mesin,
\end{abstract}


penyediaan bahan baku, proses produksi, sampai pemasaran produk. Hasil kegiatan telah terbentuk unit usaha Pusat Produksi Mesin-mesin Teknologi Tepat Guna Pascapanen Kopi. Unit usaha ini telah melakukan inovasi mesin teknologi pascapanen kopi. Produk inovasi dari Pusat Produksi Mesin-mesin Teknologi Tepat Guna Pascapanen Kopi antara lain mesin pulper mobile, mesin pencuci biji kopi, mesin huller mobile dan huller multi fungsi, dan mesin sortasi biji kopi sistem getar. Mesin-mesin TTG tersebut mempunyai keunggulan dari konstruksi dan mobilisasi dibandingkan produk yang telah beredar dipasaran selama ini. Pemasaran produk telah dilakukan melalui showroom sebagai tempat lokasi pamer produk, website penjualan, dan toko online.

Kata kunci: Inovasi, teknologi pascapanen, kopi, produk intelektual kampus.

\section{Pendahuluan}

Kopi merupakan salah satu komoditas penting dalam perdagangan dunia yang melibatkan beberapa negara produsen dan banyak negara konsumen. Data Direktorat Jenderal Perkebunan, areal perkebunan kopi di Indonesia pada tahun 2015 mencapai lebih dari 1,24 juta hektar, 933 hektar perkebunan robusta dan 307 hektar perkebunan arabika dengan total produksi sebesar 685 ton dimana 90\% diantaranya yaitu areal perkebunan kopi rakyat. Laju perkembangan areal kopi di Indonesia rata-rata mencapai sebesar 2,11\% per tahun (Perkebunan, 2014) Menurut data dari Asosiasi Eksportir Kopi Indonesia (AEKI), para petani Indonesia bersama dengan kementerian-kementerian terkait berencana untuk memperluas perkebunan-perkebunan kopi Indonesia, sambil meremajakan perkebunanperkebunan lama melalui program intensifikasi. Dengan meningkatkan luas perkebunan, produksi kopi Indonesia dalam 10 tahun ke depan ditargetkan untuk mencapai antara 900 ribu ton sampai 1,2 juta ton per tahun (Eksportir \& Indonesia, 2014). Peningkatan produksi kopi juga terjadi di provinsi Aceh, khususnya di kabupaten Aceh tengah, Bener Meriah, dan Gayo Lues. Menurut Thurmizi (2014), produksi kopi Aceh mencapai 48.282 ton dengan luas area 123.746 Ha.

Perkembangan produksi kopi yang cukup pesat tersebut perlu didukung dengan kesiapan teknologi dan sarana pascapanen yang cocok untuk kondisi petani agar mereka mampu menghasilkan biji kopi dengan mutu seperti yang dipersyaratkan oleh Standard Nasional Indonesia. Keberhasilan pengembangan teknologi pascapanen tergantung dari keberhasilan sistem inovasi teknologi dan pendampingan (Stathers et al., 2013). Adanya jaminan mutu yang pasti, ketersediaan dalam jumlah yang cukup dan pasokan yang tepat waktu serta keberlanjutan merupakan beberapa persyaratan yang dibutuhkan agar biji kopi rakyat dapat dipasarkan pada tingkat harga yang lebih menguntungkan. Untuk memenuhi persyaratan tersebut penanganan pascapanen kopi rakyat harus dilakukan dengan tepat waktu, tepat cara dan tepat jumlah seperti halnya produk pertanian yang lain.

Pascapanen hasil pertanian adalah semua kegiatan yang dilakukan sejak proses penanganan hasil pertanian sampai dengan proses yang menghasilkan produk setengah jadi (produk antara/intermediate). Penanganan pascapanen bertujuan untuk menurunkan kehilangan hasil, menekan tingkat kerusakan, dan meningkatkan daya simpan dan daya guna komoditas untuk memperoleh nilai tambah (Setyono, 2010). Penanganan pascapanen yang tidak baik akan menyebabkan terjadinya kehilangan hasil, baik bobot maupun kualitas produk yang dihasilkan, terutama untuk panen musim hujan (Firmansyah, et al., 2007). Sebagai contoh, salah satu penanganan pasca panen yang sangat dibutuhkan petani kopi adalah pengeringan (Sary, 2016).

Menurut Mayrowani (2013), kegiatan penanganan pascapanen tanaman perkebunan didefinisikan sebagai suatu kegiatan penanganan produk hasil perkebunan, yaitu sejak pemanenan hingga siap menjadi bahan baku atau produk 
akhir siap dikonsumsi. Seperti telah disebutkan di atas, teknologi pascapanen kopi juga dibedakan menjadi dua kelompok kegiatan besar, yaitu pertama: penanganan primer yang meliputi penanganan komoditas hingga menjadi produk setengah jadi atau produk siap olah, dimana perubahan/transformasi produk hanya terjadi secara fisik, sedangkan perubahan kimiawi biasanya tidak terjadi pada tahap ini. Kedua: penanganan sekunder, yakni kegiatan lanjutan dari penanganan primer, dimana pada tahap ini akan terjadi perubahan bentuk fisik maupun komposisi kimiawi dari produk akhir melalui suatu proses pengolahan. Penerapan teknologi pascapanen berkaitan dengan kondisi sosial budaya setempat, sehingga kebijakankebijakan yang dibuat harus tidak mendistorsi kondisi sosial ekonomi setempat, namun demikian tetap mampu mengakomodasi misi nasional yaitu peningkatan produksi dan mutu hasil.

Proses pascapanen kopi dimulai dari panen buah kopi yang telah masak, penyortiran buah yang superior dari buah inferior, pengupasan kulit buah kopi, fermentasi, pencucian, pengeringan, pengupasan kulit HS (hasil dari proses pengupasan kulit buah adalah biji yang masih memiliki kulit tanduk disebut biji kopi HS), sortir biji kering dan pengemasan atau penyimpanan. Mesin-mesin pascapanen kopi seperti pengupasan kulit buah kopi, pencucian, pengupasan kulit HS dan sortasi telah banyak diproduksi dan dijual di pasaran. Mesin-mesin tersebut mempunyai konstruksi yang berat dan tidak mudah untuk dipindahpindahkan (non mobile). Hal tersebut menyebabkan proses pengolahan kopi pasca panen menjadi terbatas dan tidak efektif.

Penerapan teknologi tepat guna pascapanen kopi merupakan salah satu cara untuk meningkatkan nilai tambah komoditas perkebunan kopi. Kelompok tani BLJ Tani (Blang Jorong Tani) dan kelompok tani Buge Mujadi adalah dua kelompok tani petani kopi di Bener Meriah yang menjadi masyarakat mitra kegiatan penerapan TTG. Tujuan dari kegiatan penerapan TTG ini adalah untuk meningkatkan produktifitas masyarakat mitra (petani kopi). Metode pelaksanaan program dimulai dari survey ke lokasi, sosialisasi program, perancangan dan pembuatan mesinmesin pascapanen kopi, penerapan mesin yang telah difabrikasi dan evaluasi kegiatan. Dari hasil kegiatan telah diproduksi mesin-mesin tepat guna pascapanen kopi. Hasil evaluasi kegiatan menunjukan produktifitas petani kopi mulai meningkat. Hal ini dapat terlihat dari proses pengolahan kopi pascapanen yang lebih efektif dan efesien (Mawardi et al., 2019).

Beberapa daerah pelosok Indonesia saat ini masih banyak ditemukan petanipetani kopi tradisional yang sangat membutuhkan fasilitas guna meningkatkan kualitas dari hasil pertanian kopinya. Disisi lain keberadaan teknologi pascapanen kopi yang telah ada di pasaran memiliki konstruksi yang besar dan berat, harga yang relatif tinggi dan tidak memenuhi kearifan lokal. Permasalahan ini menjadi dasar terbentuknya Program Pengembangan Usaha Produk Intelektual Kampus (PPUPIK) Pusat Produksi Mesin-mesin Teknologi Tepat Guna (TTG) Pascapanen Kopi Politeknik Negeri Lhokseumawe.

Upaya pengembangan budaya ekonomi berbasis pengetahuan (knowledge based economy), perguruan tinggi perlu diberi akses dalam wujud knowledge and technopark yang memanfaatkan pengetahuan, pendidikan maupun hasil riset dosen. Beberapa program kreativitas dan inovasi kampus atau pengembangan usaha produk intelektual kampus telah dilaporkan. Program pengembangan usaha produk intelektual kampus (PPMU-PPUPIK): produk tuna nut cookies telah terlaksana di Jurusan Perikanan Fakultas Ilmu Kelautan dan Perikanan Universitas Hasanuddin. Hasil pelaksanaan kegiatan memperlihatkan usaha olahan tuna nut cookies, memiliki prospek yang sangat baik. Tingkat keberhasilan penjualan 99\%, tingkat penerimaan usaha sebesar $49.5 \%$. Nilai investasi $13 \%$ per bulan (Adhawati et al., 2019) 
Ipteks Bagi Kreativitas dan Inovasi Kampus; Produk Olahan Ikan Berbasis Surimi telah dilaksnakan di Fakultas Pertanian, Universitas Hasanuddin. Metode yang digunakan adalah mendirikan unit bisnis usaha pengolahan otak-otak berbasis surimi dan abon di Laboratorium Pengembangan Produk Fakultas Pertanian Universitas Hasanuddin. Hasil yang diperoleh dari kegiatan ini adalah terbentuknya unit bisnis, pemasaran yang dilakukan dalam bentuk penjualan langsung dan pameran serta adanya merek dagang "Aroma Laut" dari produk otakotak (Tawali et al., 2018). Jurusan Ilmu Tanah dan Sumber Daya Lahan, Faperta Universitas Papua telah melaporkan hasil kegiatan Iptek bagi Inovasi dan Kreativitas Kampus (IbIKK) berupa produksi pupuk fosfat-plus. Kegiatan IbIKK pupuk ini merupakan pemanfaatan salah satu produk Intelektual Kampus Universitas Papua untuk memperoleh manfaat ekonomi. Formula pupuk ini dibuat dengan mencampurkan fosfat alam lokal, bahan organik dan formula tambahan sesuai kebutuhan jenis tanaman. Pada tahun ke-1 program ini telah menghasilkan tiga jenis pupuk organik dan semi organik yaitu: pupuk kompos, pupuk kotoran ternak, pupuk fosfat cair-plus, pupuk fosfat-plus granul (Musaad et al., 2018).

Program PPUPIK diharapkan mampu mendorong perguruan tinggi dalam membangun akses untuk menghasilkan produk jasa dan/atau teknologi hasil ciptaannya sendiri. Misi program PPUPIK adalah menciptakan akses sosialisasi produk-produk intelektual dosen di lingkungan perguruan tinggi dalam rangka memenuhi kebutuhan masyarakat baik internal maupun ekternal kampus. Perguruan tinggi berpeluang memperoleh pendapatan dan membantu menciptakan wirausaha baru.

PPUPIK, Politeknik Negeri Lhokseumawe, merupakan salah satu skim pengabdian kepada masyarakat. Tujuan pengabdian skim PPUPIK Pusat Produksi Mesin-mesin TTTG Pascapanen Kopi Politeknik Negeri Lhokseumawe adalah (1) Tersedianya unit usaha yang memproduksi mesin-mesin TTG pascapanen kopi dalam upaya menuju menambah pendapatan kampus, (2) Memproduksi mesinmesin TTG pascapanen kopi berbasis intelektual kampus, yang mempunyai daya saing dipasar nasional, dan (3) Meningkatkan produktifitas petani kopi melalui mekanisasi proses pascapanen kopi dengan melakukan pengembangan atau inovasi mesin-mesin teknologi tepat guna pascapanen kopi. Kegiatan ini juga sebagai wadah sosialisasi hasil riset dosen berbasis produk untuk kebutuhan masyarakat, disamping itu juga sebagai tempat menciptakan wirausahaan baru.

\section{Metode Pelaksanaan}

Tempat dan Waktu. Tempat kegiatan pengabdian PPUPIK Pusat Produksi Mesinmesin Teknologi Tepat Guna Pascapanen Kopi Politeknik Negeri Lhokseumawe dilaksanakan di Jurusan Teknik Mesin kampus Politeknik Negeri Lhokseumawe dan workshop Pusat Produksi Mesin-mesin Teknologi Tepat Guna Pascapanen Kopi beralamat di Jalan Banda Aceh-Medan km 270 Cunda Lhokseumawe. Kegiatan dilaksanakan dalam kurun tiga tahun, dimulai pada tahun 2017 sampai 2019.

Khalayak Sasaran. Khalayak sasaran dari kegiatan ini adalah masyarakat umum, khususnya petani kopi, baik perorangan maupun kelompok tani. Produk PPUPIK Politeknik Negeri Lhokseumawe dapat berguna bagi petani kopi atau kelompok tani kopi yang berada di Aceh khususnya dan petani kopi diseluruh Indonesia pada umumnya.

Metode Pengabdian. Kegiatan PPUPIK bermitra dengan kampus (Politeknik Negeri Lhokseumawe). Bentuk kemitra dilakukan dengan penyediaan dana pendamping, penyediaan fasilitas produksi, ruang pamer dan pemasaran. Metode kegiatan PPUPIK Pusat Produksi Mesin-mesin Teknologi Tepat Guna Pascapanen Kopi Politeknik Negeri Lhokseumawe dibagi dalam tiga tahapan, yaitu tahapan produksi, pemasaran dan pendirian unit usaha. Tahapan produksi dimulai dari mendesain 
konstruksi mesin-mesin TTG pascapanen kopi, penyediaan bahan habis pakai (standar dan non standar), pembuatan (fabrikasi dan perakitan), uji kinerja. Tahapan pemasaran produk dilakukan melalui pembuatan brosur penjualan, penyediaan ruang pamer, penjualan di toko online, pembuatan website penjualan dan mengikuti pameran. Tahapan pendirian unit usaha dimulai dari pengusulan pendirian kepada pihak institusi, analisa kelayakan, dan penerbitan surat keputusan Direktur Politeknik Negeri Lhokseumawe.

Indikator Keberhasilan. Indikator keberhasilan kegiatan dapat dilihat dari terbentuknya unit usaha yang memproduksi mesin-mesin TTG pascapanen kopi di Politeknik Negeri Lhokseumawe, berjalannya kegiatan usaha produksi yang memproduksi 8 (delapan) varian mesin-mesin TTG pascapanen kopi sebanyak 15 unit. Indikator keberhasilan pemasaran dapat diukur dengan tersedianya brosur penjualan, tersedianya ruang pamer, produk terjual secara online dan pada tahap awal terjualnya mesin-mesin TTG pascapanen kopi minimal sebanyak 4 unit.

Metode Evaluasi. Evaluasi dilakukan untuk melihat tingkat keberhasilan dari kegiatan dan dilakukan secara bertahap (Rifa'i, dkk., 2017, 2018; Kudsiah, dkk., 2018). Metode evaluasi pada tahapan produksi dilakukan dengan mengevaluasi rancangan mesin yang akan diproduksi, proses produksi (ketersediann bahan baku dan fasilitas penunjang), uji kinerja mesin dan teknik pemasaran yang dilakukan. Evaluasi pendirian unit usaha dilakukan dengan analisa kelayakan usaha yang meliputi produksi (fasilitas produksi dan kompetisi tenaga kerja), pemasaran, dan cashflow usaha.

\section{Hasil dan Pembahasan}

\section{A. Produksi Mesin-Mesin TTG Pascapanen Kopi}

Buah kopi hasil panen perlu segera diproses menjadi bentuk akhir yang lebih stabil agar aman untuk disimpan dalam jangka waktu tertentu. Untuk itu diperlukan suatu acuan sebagai pegangan bagi petani dan/atau pengolah dalam menghasilkan produk yang dipersyaratkan pasar. Salah satu proses teknologi dalam produksi kopi adalah teknologi pascapanen. Teknologi pascapanen mempunyai peranan penting dalam peningkatan nilai tambah komoditas pertanian melalui proses pengolahan hasil pertanian. Penerapan teknologi pascapanen secara baik membuat usaha tani menjadi lebih efisien dari sisi mikro dan dapat merupakan peluang peningkatan produksi dengan mengurangi tingkat kehilangan hasil pada saat panen maupun rendahnya mutu hasil.

Pusat Produksi Mesin-mesin Teknologi Tepat Guna Pascapanen Kopi Politeknik Negeri Lhokseumawe telah memproduksi beberapa mesin teknologi pascapanen kopi. TTG yang dikembangkan membuat pekerjaan petani kopi semakin mudah serta mampu meningkatkan nilai ekonomi. Selain itu TTG yang dikembangkan juga disesuaikan dengan aspek-aspek lingkungan, berkaitan erat dengan kondisi lokal, kebudayaan, sosial, politik, dan ekonomi masyarakat

Pada tahapan produksi, Pusat Produksi Mesin-mesin Teknologi Tepat Guna Pascapanen Kopi Politeknik Negeri Lhokseumawe telah memproduksi 8 (delapan) varian TTG pascapanen kopi. Varian TTG pascapanen kopi yang telah diproduksi antara lain; mesin pengupas kulit buah kopi dengan varian pulper mobile dengan penambahan mekanisme bajak (4 unit) dan non bajak (1 unit), mesin pencuci biji kopi ( 3 unit), mesin pengupas biji kopi kering dengan varian huller machine (3 unit), mobile huller machine ( 2 unit), dan mobile huller machine multi fungsi (1 unit), dan mesin sortasi biji kopi dengan sistem getar (1 unit). Gambar 1 memperlihatkan mesin-mesin yang telah diproduksi oleh Pusat Produksi Mesin-mesin Teknologi Tepat Guna Pascapanen Kopi Politeknik Negeri Lhokseumawe.

Proses pengupas kulit buah kopi adalah salah satu proses awal setelah sortasi buah kopi. Proses pengupas kulit buah kopi biasanya menggunakan mesin mengupas (pulper) tipe silinder. Mesin pulper produksi pusat produksi mesin-mesin 

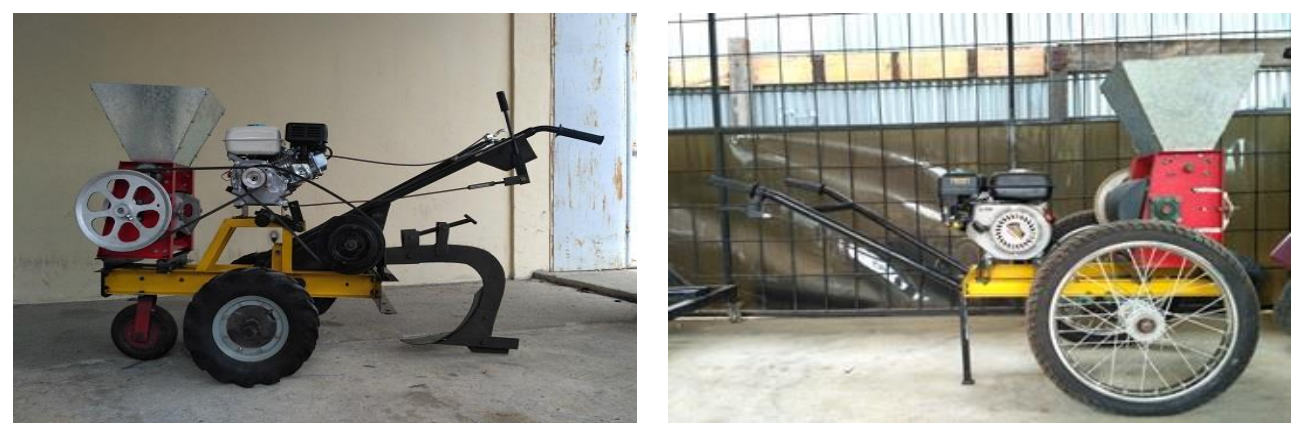

(a) Pullper machine
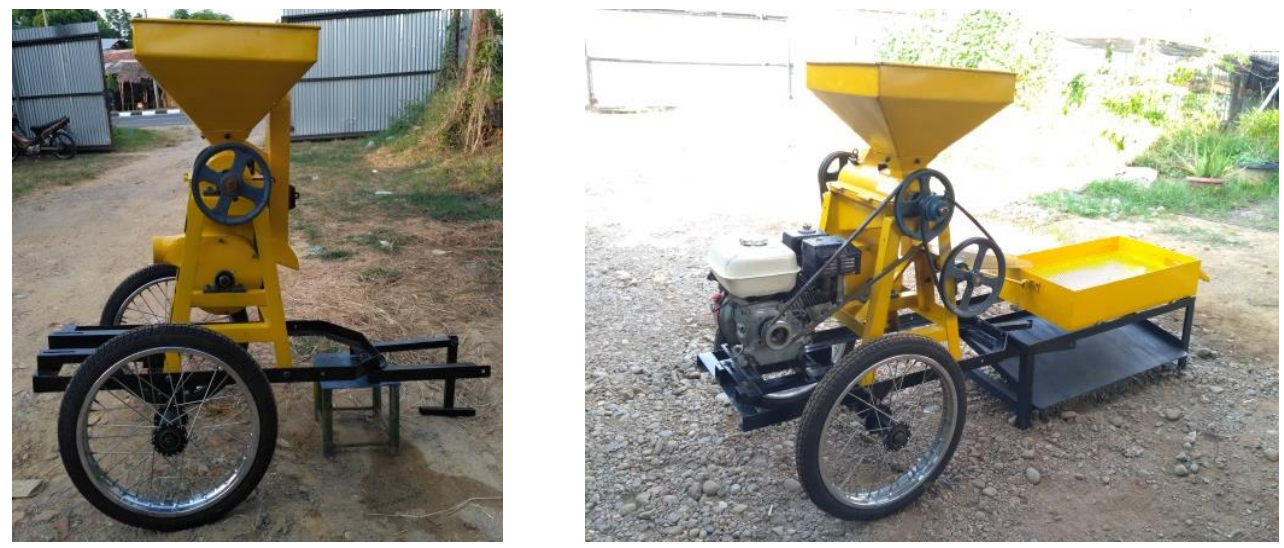

(b) Huller machine
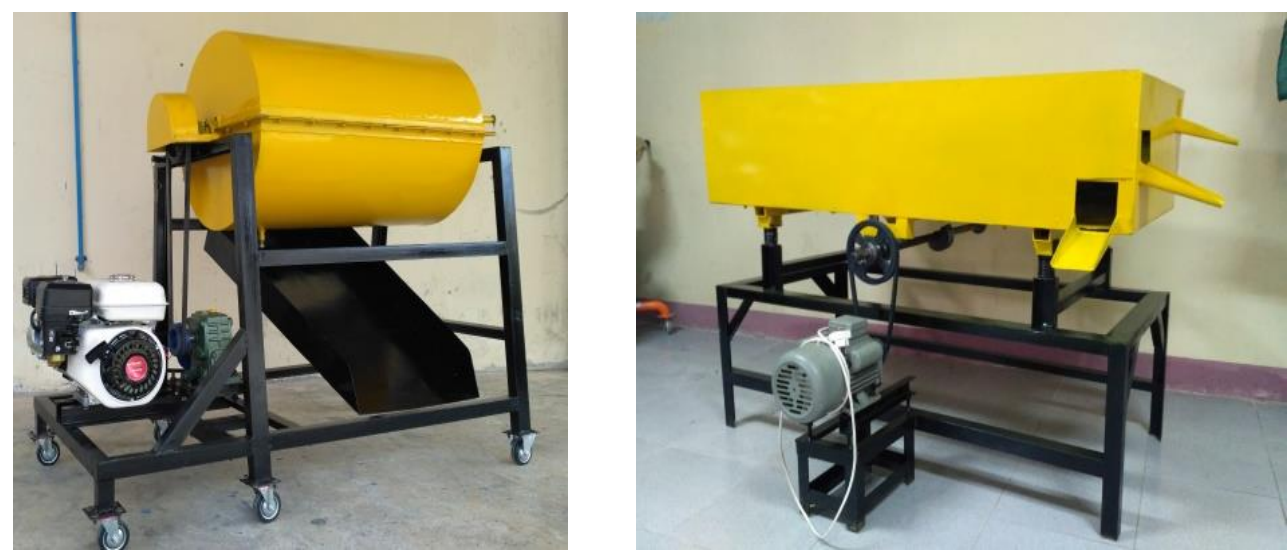

(c) Mesin cuci dan sortir biji kopi

Gambar 1. Mesin-mesin pascapanen kopi produk Pusat Produksi Mesin-mesin Teknologi Tepat Guna Pascapanen Kopi Politeknik Negeri Lhokseumawe

teknologi tepat guna pascapanen kopi terdiri dari dua model, yaitu type pulper portable dengan mata bajak dan pulper mobile. Tipe pulper portable dengan mata bajak mempunyai keunggulan dalam mobilisasi dan dapat berfungsi ganda sebagai trantor untuk membajak lahan kopi, sedangkan type pulper mobile mempunyai keunggulan dalam mobilisasi. Jika kita bandingkan dengan konstruksi mesin pengupas kulit buah kopi yang beredar di pasaran, mesin pulper yang dihasilkan oleh Pusat Produksi Mesin-mesin Teknologi Tepat Guna Pascapanen Kopi Politeknik Negeri Lhokseumawe mempunyai banyak keunggulan, baik dari konstruksi maupun fungsionalnya. Konstruksi mesin pegupas kulit buah kopi yang beredar di pasaran atau yang telah ada selama ini memiliki konstruksi yang berat dan tidak mudah untuk dipindah-pindahkan (tidak mobile). Hal ini menyebabkan proses pengupasan kulit menjadi terbatas pada lokasi tertentu. 
Pengupasan kulit biji kopi (huller machine) bertujuan untuk memisahkan biji kopi dari kulit tanduk sehingga menghasilkan biji kopi beras. Mesin huller produksi Pusat Produksi Mesin-mesin Teknologi Tepat Guna Pascapanen Kopi mempunyai keunggulan dalam mobilisasi sehingga proses pengupasan akan lebih efektif dan efesien. Terdapat dua tipe mesin huller yang diproduksi yaitu tipe huler mobile dan huller multi fungsi. Huller mobile mempunyai keungulan dalam mobilasi dan huller multi fungsi mempunyai keunggulan pada waktu proses. Huller multi fungsi merupakan mesin yang mengintegrasikan proses hulling dan proses sortasi biji kopi.

Pencucian biji kopi bertujuan untuk menghilangkan sisa lendir hasil fermentasi yang masih menempel di kulit tanduk. Mesin pencuci biji kopi tipe batch yang diproduksi oleh Pusat Produksi Mesin-mesin TTG Pascapanen Kopi Politeknik Negeri Lhokseumawe mempunyai kapasitas pencuncian kopi 100-200 kg per jam. Kebutuhan air pencuci yang minim dan proses yang cepat membuat mesin pencuci biji kopi ini sangat cocok untuk petani kopi per orangan maupun kelompok. Ada dua type mesin cuci biji kopi yaitu type batch dan type batch mobile.

Mesin sortir biji kopi yang diproduksi oleh Pusat Produksi Mesin-mesin TTG Pascapanen Kopi Politeknik Negeri Lhokseumawe menyortir besaran dimensi dari biji kopi dengan tiga tingkatan, yaitu besar, sedang dan kecil, sesuai dengan ketentuan SNI 01-2907-2008. Mesin sortir biji kopi mempunyai kapasitas sortir 100-200 kg per jam. Mesin sortir biji kopi yang diproduksi menggunakan mekanisme getar yang dihasilkan dari bantul yang unbalance.

\section{B. Pemasaran Mesin-Mesin TTG Pascapanen Kopi}

Produk mesin-mesin pascapanen kopi yang dihasilkan oleh pusat produksi mesin-mesin teknologi tepat guna pascapanen kopi Politeknik Negeri Lhokseumawe terus diproduksi sesuai dengan permintaan konsumen. Strategi pemasaran produk dilakukan melalui penyediaan brosur, showroom, penjualan di toko online, dan website penjualan.
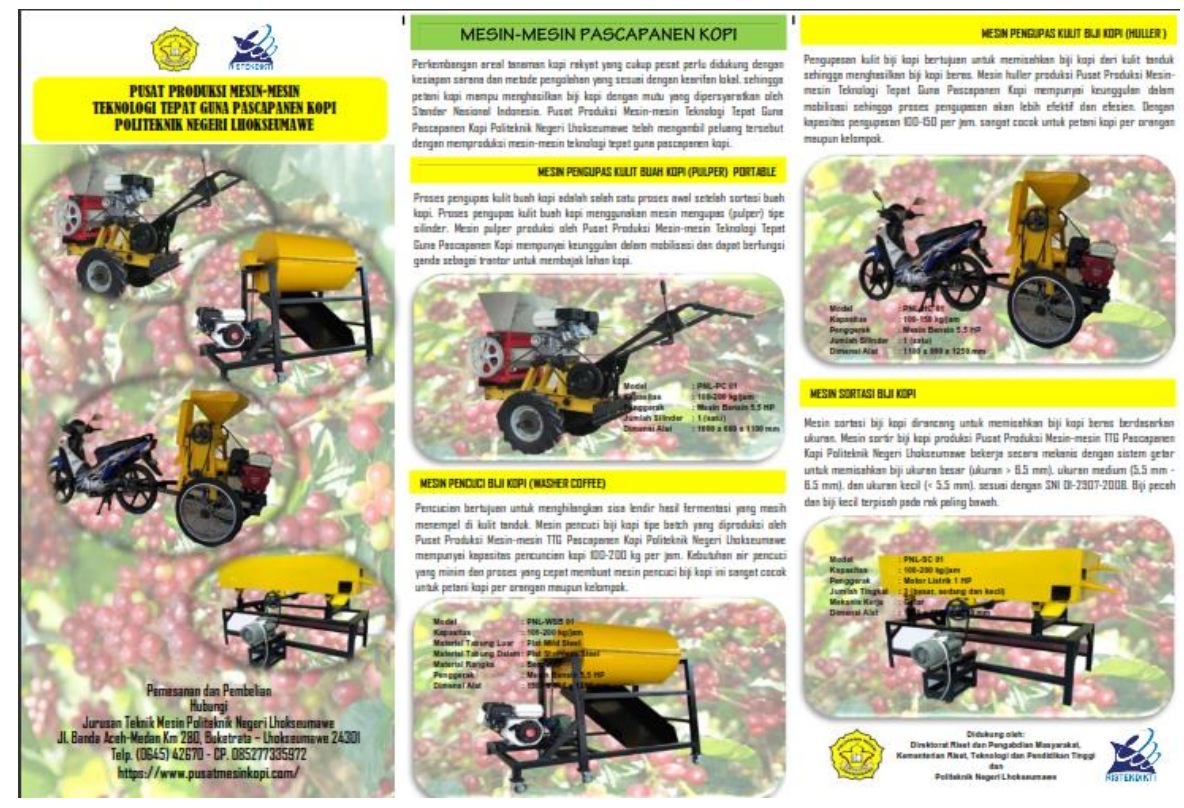

Gambar 2. Brosur produk mesin TTG pascapanen kopi

Gambar 2 memperlihatkan brosur produk yang dihasilkan. Selain melalui brosur yang memuat spesifikasi mesin-mesin yang diproduksi, konsumen juga dapat langsung datang ke showroom untuk melihat langsung produk secara langsung. Showroom pusat produksi mesin-mesin teknologi tepat guna pascapanen kopi Politeknik Negeri Lhokseumawe beralamat di jalan raya Banda Aceh-Medan 
Km. 270, Cunda, Lhokseumawe (Gambar 3). Dalam upaya meningkatkan pemasaran, pusat produksi mesin-mesin teknologi tepat guna pascapanen kopi Politeknik Negeri Lhokseumawe juga telah membuat website penjualan (Gambar 4) dan menjual melalui situs jual online BUKALAPAK.COM (Gambar 5).

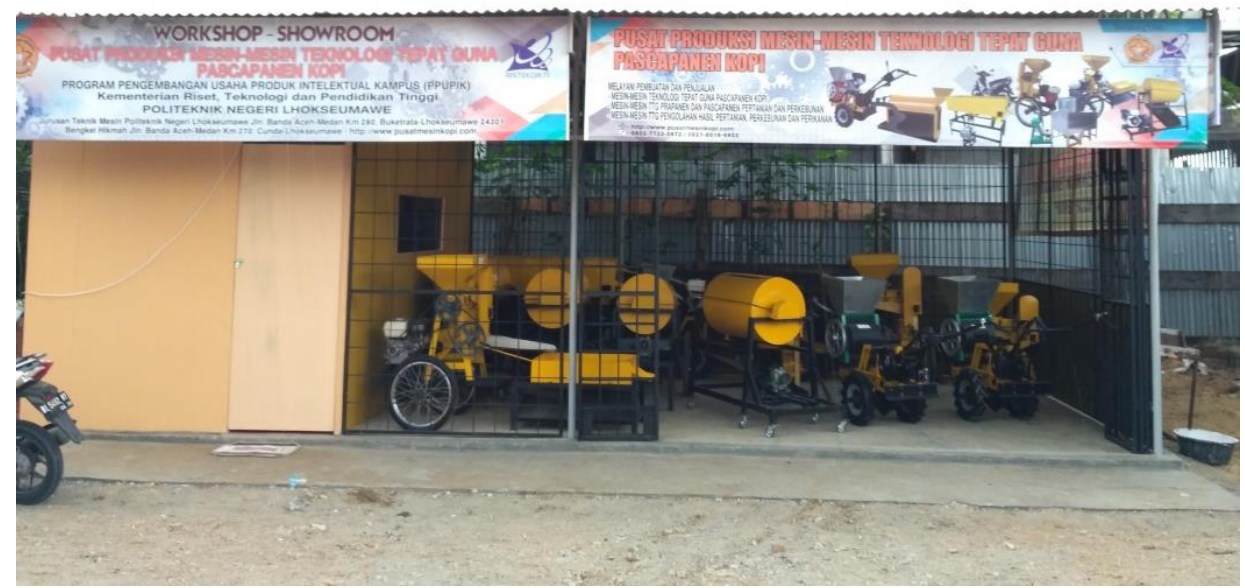

Gambar 3. Showroom pusat produksi mesin-mesin teknologi tepat guna pascapanen kopi Politeknik Negeri Lhokseumawe

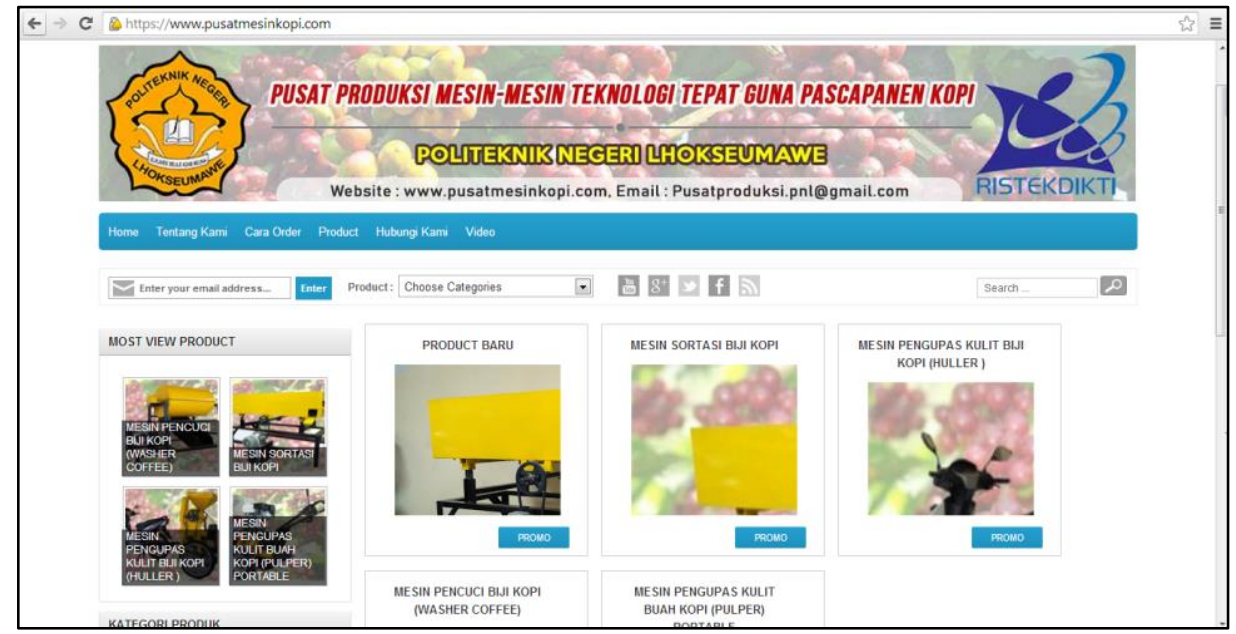

Gambar 4. Website pusat produksi mesin-mesin teknologi tepat guna pascapanen kopi Politeknik Negeri Lhokseumawe

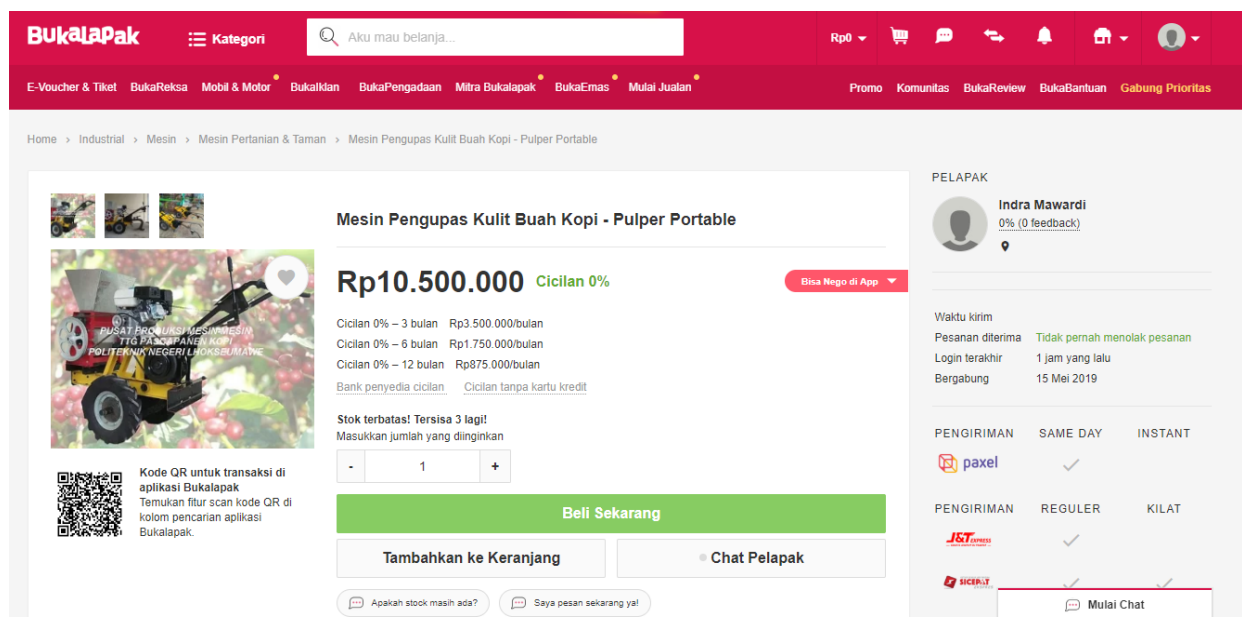

Gambar 5. Penjualan produk unit usaha melalui situs online

Jurnal Panrita Abdi, 2020, Volume 4, Issue 1. 


\section{Pendirian Unit Usaha}

Pengesahan pusat produksi mesin-mesin teknologi tepat guna pascapanen kopi sebagai unit usaha di Politeknik Negeri Lhokseumawe dilakukan setelah melalui dua tahun berjalannya produksi. Analisa kelayakan telah dilakukan oleh tim penilai badan Usaha Kampus dan penerbitan Surat Keputusan Direktur Politeknik Negeri Lhokseumawe Nomor 1305 Tanggal 5 Agustus 2019.

Struktur organisasi meliputi penanggung jawab, penasehat, manajer dan kepala bidang desain dan pengembangan, kepala bidang produksi, dan kepala bidang pemasaran. Susunan organisasi pusat produksi mesin-mesin teknologi tepat guna pascapanen kopi Politeknik Negeri Lhokseumawe diperlihatkan pada gambar 6.

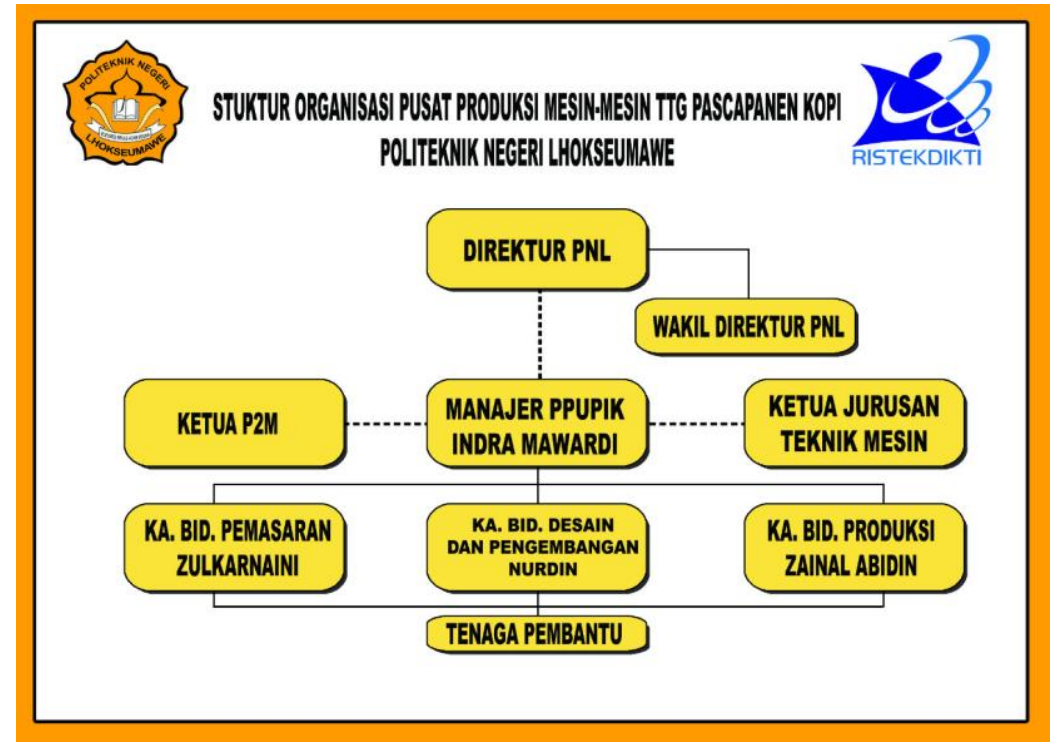

Gambar 6. Struktur organisasi pusat produksi mesin-mesin TTG pascapanen kopi Politeknik Negeri Lhokseumawe

\section{Kesimpulan}

Kegiatan pengabdian Program Pengembangan Usaha Produk Intelektual Kampus (PPUPIK) Politeknik Negeri Lhokseumawe telah berhasil membentuk Pusat Produksi Mesin-mesin Teknologi Tepat Guna Pascapanen Kopi sebagai satu unit usaha bisnis di Politeknik Negeri Lhokseumawe. Pusat Produksi Mesin-mesin Teknologi Tepat Guna Pascapanen Kopi telah melakukan inovasi pada mesin teknologi pascapanen kopi. Produk inovasi dari Pusat Produksi Mesin-mesin Teknologi Tepat Guna Pascapanen Kopi telah memproduksi 8 (delapan) varian mesin TTG pascapanen kopi sebanyak 15 unit. Varian mesin tersebut antara lain mesin pulper mobile, mesin pencuci biji kopi, mesin huller mobile dan huller multi fungsi, dan mesin sortasi biji kopi sistem getar. Mesin-mesin TTG tersebut mempunyai keunggulan dari konstruksi dan mobilisasi dibandingkan produk yang telah beredar dipasaran selama ini. Mesin teknologi pascapanen kopi yang diproduksi telah disosialisasikan kepada petani kopi, khususnya petani kopi di wilayah provinsi Aceh. Pemasaran dilakukan melalui toko online, website, dan pameran di showroom.

\section{Ucapan Terima Kasih}

Penulis mengucapkan terima kasih kepada Kemenristekdikti melalui pendanaan hibah Pengabdian kepada Masyarakat skim Program Pengembangan Usaha Produk Intelektual Kampus (PPUPIK) Tahun 2019. 


\section{Referensi}

Adhawati, S. S., Fakhriyah, S., \& Suwarni, S. (2019). Program Pengembangan Usaha Produk Intelektual Kampus (PPMU-PPUPIK): Produk Tuna Nut Cookies. Panrita Abdi-Jurnal Pengabdian Pada Masyarakat, 3(1), 61-69.

Eksportir, A., \& Indonesia, I. K. (2014). Konsumsi kopi domestik. Diambil dari http://www. aeki-aice. org/page/konsumsi-kopi-domestik/id.

Firmansyah, I.U., M. Aqil, dan Y. S. (2007). Penanganan Pascapanen Jagung; Teknik Produksi dan Pengembangan. Puslitbang Tanaman Pangan.

Kudsiah, H., Tresnati, J., \& Ali , S. A. (2018). IbM Kelompok Usaha Bandeng Segar Tanpa Duri di Kabupaten Pangkep Sulawesi Selatan. Panrita Abdi Jurnal, 2(1), 55-63.

Mawardi, I., Hanif, H., Zaini, Z., \& Abidin, Z. (2019). Penerapan Teknologi Tepat Guna Pascapanen Dalam Upaya Peningkatan Produktifitas Petani Kopi di Kabupaten Bener Meriah. CARADDE: Jurnal Pengabdian Kepada Masyarakat, $1(2), 205-213$.

Mayrowani, H. (2013). Kebijakan penyediaan teknologi pascapanen kopi dan masalah pengembangannya. Forum Penelitian Agro Ekonomi, 31(1), 31-49.

Musaad, I., Wibowo, K., \& Kubangun, S. H. (2018). Usaha IbIKK pupuk Fosfat-Plus. Panrita Abdi-Jurnal Pengabdian Pada Masyarakat, 2(1), 1-7.

Perkebunan, D. J. (2014). Statistik Perkebunan Indonesia: Kopi 2013-2015. Kementerian Pertanian. Jakarta.

Rifa'i, M.A., Kudsiah, H., \& Muzdalifah. (2017). Alih teknologi produksi benih anemon laut secara aseksual. Jurnal Panrita Abdi, 1(1), 33-39.

Rifa'i, M.A., Syahdan, M., Muzdalifah, \& Kudsiah, H. (2018). Pengembangan Usaha Produk Intelektual Kampus: Anemon Laut Ornamen. Jurnal Panrita Abdi, 2(1), 40-47.

Sary, R. (2016). Kaji eksperimental pengeringan biji kopi dengan menggunakan sistem konveksi paksa. Journal of POLIMESIN, 14(2), 13-18.

Setyono, A. (2010). Perbaikan teknologi pascapanen dalam upaya menekan kehilangan hasil padi. Pengembangan Inovasi Pertanian, 3(3), 212-226.

Stathers, T., Lamboll, R., \& Mvumi, B. (2013). Post-harvest agriculture in a changing climate. Rural 21: The International Journal for Rural Development, $47(4), 12-14$.

Tawali, A. B., Asfar, M., Suhendar, N. K., \& Mahendaradatta, M. (2018). Ipteks Bagi Kreativitas dan Inovasi Kampus; Produk Olahan Ikan Berbasis Surimi. Panrita Abdi-Jurnal Pengabdian Pada Masyarakat, 2(1), 8-14.

Thurmizi. (2014). Potensi dan Pengembangan Kopi di Aceh. Indonesia International Coffee Symposium 2014. Banda Aceh.

Penulis:

Indra Mawardi, Jurusan Teknik Mesin, Politeknik Negeri Lhokseumawe, Aceh.

E-mail: indratm@pnl.ac.id

Nurdin, Jurusan Teknik Mesin, Politeknik Negeri Lhokseumawe, Aceh.

E-mail: nurdinhusin@yahoo.com

Zulkarnaini, Jurusan Tata Niaga, Politeknik Negeri Lhokseumawe, Aceh.

E-mail: Jo312006@yahoo.com

Bagaimana men-sitasi artikel ini: Mawardi, I., Nurdin, \& Zulkarnaini, (2020). Inovasi Mesin-Mesin Teknologi Pascapanen Kopi sebagai Produk Usaha Intelektual Kampus Politeknik Negeri

Lhokseumawe. Jurnal Panrita Abdi, 4(1), 24-33. 